\title{
Implementing Skilled Midwifery Services in Dhaka City Urban Area: Experience from Community Based Safe Motherhood Project, Bangladesh
}

\author{
S TASNIM $^{\mathrm{A}}$, A RAHMAN ${ }^{\mathrm{B}}, \mathrm{F} \mathrm{RAHMAN}^{\mathrm{C}}, \mathrm{N} \mathrm{KABIR}^{\mathrm{D}}, \mathrm{F} \mathrm{ISLAM}^{\mathrm{E}}$, \\ $S_{\text {S CHOWDHURYF }}$, AKM SHAHABUDDING
}

\begin{abstract}
Summary:
In Bangladesh majority of deliveries are attended by unskilled traditional birth attendants and maternal mortality is still quite high. Global evidence suggests that most critical intervention for reduction of maternal mortality is to ensure skilled attendance at birth.
\end{abstract}

The objective of this study was to explore the effect of strengthening obstetric care services through implementation of skilled Midwives at selected urban centres in terms of utilization of antenatal and delivery care in the community.

A quasi experimental community trial was conducted during January 2000 to June 2003. Ten health centers were selected from the maternity care centers of urban primary health care project in Dhaka city, matched into comparable pair and assigned randomly as intervention and control centers. The intervention consisted of deployment of 10 skilled midwives in pair to provide obstetric care services in five intervention centre and the community. Essential drugs and

Introduction:

Every year 529,000 women die of pregnancy related complications throughout the world ${ }^{1}$. Ninety nine percent of such deaths occurs in developing countries ${ }^{2}$.

a. Dr Saria Tasnim. FCPS, MMEd, Diploma in community Epidemiology, Associate Professor, Gynae. ICMH.

b. Dr Aminur Rahman. DCM. MMEd. Technical Director, Centre for Injury Prevention and Research, Bangladesh

c. Dr Fazlur Rahman. DCM. Phd., Executive Director, Centre for Injury Prevention and Research, Bangladesh

d. Nazneen Kabir. FCPS. DAGO.Associate Professor, Gynae. ICMH.

e. Prof Ferdousi Islam. FCPS, MMEd. Professor \& Head of Obstetrics \& Gynae. ICMH

f. Prof Sameena Chowdhury. Professor (Retd) of Obstetrics \& Gynae, ICMH.

g. Prof A K M Shahabuddin. Professor (Retd) of Obstetrics \& Gynae, ICMH.

Address of Correspondence: Dr Saria Tasnim. Associate Professor of Gynaem Institute of Child and Mother Health. Matuail, Dhaka1362, Mobile : 01819221096, e mail: sariatasnim2007@gmail.com

Accepted: 26 September 2009 logistics were supplied to both intervention and control centers for optimizing the function.

A total of 6077 mothers having less than one year child were interviewed. There was significant improvement from baseline in the utilization of antenatal care services (6.1 vs. $2.1 \%, p<0.001$ ), availing antenatal visits 5 times or more (13.4\% vs. 8.1\%, $p<0.001)$, consultation with skilled health care providers for pregnancy complication (9.3\% vs. $5.7 \%$, $p<0.001)$, institutional delivery $(7.3 \%$ vs. $4.1 \%, p<0.001)$ and delivery by skilled birth attendant (9.4\% vs. 5.8\%, $p<0.001)$ between intervention and control area respectively.

The intervention of deployment of skilled midwives improved utilization of ANC, increased institutional delivery and delivery by skilled birth attendants. The program can be scaled up to see its impact on maternal health.

Key words: skilled midwife, emergency obstetric care, urban health care, antenatal care

(J Bangladesh Coll Phys Surg 2011; 29: 10-15)

South Asia has $22 \%$ of the world's population but $50 \%$ of the world's maternal death ${ }^{3}$. Majority of such deaths result from inappropriate management of pregnancy and childbirth. About 1.4 million newborn deaths within the first week and another 1.3 million stillbirths take place in South $\mathrm{Asia}^{4}$.

In Bangladesh about 3.5 million deliveries take place annually, majority occur at home, attended by traditional birth attendants. Bangladesh health and demographic survey revealed that birth delivered in a facility was 4 \% in 1993-94, 8\% in 1999-2000, 9\% in 2004 and 15\% in $2007^{5-8}$. In urban area $21 \%$ births occur at health facilities ${ }^{8}$. Proportion of antenatal care from a trained person increased consistently and rose by 4 percent from 48 to 52 percent between 2004 and 2007 BDHS $^{7,8}$. Maternal mortality and infant mortality was reported to be 320 and 580 per 100,000 live births respectively ${ }^{9}$.

The health care in urban area is provided from 3 sources: Government, NGO and private. The public health care facilities are provided through general and specialized 
hospitals and dispensaries under ministry of Health and Family welfare. In metropolitan cities the City Corporation provide comprehensive Reproductive Health package with Emergency Obstetric Care in selected centers through its partner NGOs. However, the numbers of primary level maternity centers are inadequate in relation to the growing urban population of and there was also lack of sufficient number of professionally competent midwives ${ }^{10}$.

The experience of different programs of global Safe Motherhood initiative since 1987, have identified that presence of a skilled attendant at the time of delivery is essential to detect and manage obstetric emergencies appropriately and thereby in saving lives ${ }^{11}$. Skilled Birth attendants refer to people with midwifery skill and defined as trained nurse, midwife or doctors who have completed set course and have necessary skill to manage normal deliveries safely, recognize complication, can manage and refer if needed ${ }^{12}$. It is acknowledged that the skilled attendants should live in and are part of the community they serve, so that they can cover home deliveries $^{12}$. There is evidence that professionalisation of delivery care is a key to reducing maternal mortality. In developed countries decline in maternal mortality (between 1750 and 1850) was related both to an increasing proportion of midwives conducting deliveries and to a higher standard of midwifery ${ }^{13}$.

WHO recommends that for countries with high level of maternal mortality 60 percent of the deliveries should be conducted with skilled attendants by $2015^{14}$. Bangladesh National Maternal Health strategy has targeted to achieve 50 percent of all birth assisted by skilled birth attendant by $2010^{15}$. The objective of this study was to explore the effect of strengthening obstetric care services through implementation of skilled Midwives at selected urban centres in terms of utilization of antenatal care, delivery by skilled birth attendant, treatment for pregnancy complications and institutional delivery in the community.

\section{Method:}

This was a quasi experimental community trial conducted during January 2000 to June 2003. Ten health centers were selected systematically from about 105 primary care and 20 comprehensive reproductive health care centers under urban primary health care project in Dhaka city. They were matched into comparable pair and assigned randomly as intervention and control centers. The adjoining area containing approximately 20-25 thousand population constituted the study clusters.

The intervention consisted of training a group of diploma nurses (graduated from 3 years basic nursing with one year midwifery training) during January to December 2001 according to a competency based curriculum developed through national level workshop and expert meetings. The curriculum was standardized with WHO standards of Midwifery practice for Safe Motherhood, 1999 ${ }^{16}$. It consisted of 11 modules viz General, Behaviour Change Communication (BCC), Antenatal, Postnatal, and Intranatal Care, Life saving, Breast Feeding, Family planning, Infection Prevention and Waste Disposal, Management and Computer module. The training was of one year duration with approximately 50 working weeks (2414 hours) and time distribution of theory 338 hours (14\%) and practical 2076 hours (85\%). Participatory training methodology was adopted and there was in course and end course assessments. After graduating from the training they were designated skilled midwives and deployed in 5 intervention centers in pair during January-December 2002 to serve both in the clinic and the community. Other health care providers like doctors, nurses and paramedics were similar among control and intervention centers.

For community mobilization in the intervention area the skilled midwives conducted about 100 group meeting with pregnant and lactating mothers, husbands and elder family members each lasting for 1-1.5 hours, distributed 25,000 leaflets , arranged 10 video show on obstetric emergency, provided a number of antenatal and delivery services at patient's home. Essential drugs (like iron, folic acid and calcium tablets, oxytocin and ampicillin injections etc) and instruments (like stethoscope, BP machine, spot light, scissor, forceps etc) were supplied to both control and intervention centers according to their requirements of use. Regular supervision and monitoring of the activities were done by the researchers and different registers were maintained to record the services.

Data was collected through home visits and interviewing women having less than one year child with pre-tested structured questionnaire during August to November 2001 and November 2002 to February 2003 for baseline 
and post intervention respectively. A rapid survey of about 50,000 household were made to find out the eligible mothers and among them about 3000 were randomly selected each in baseline and post intervention survey. The data collectors were female graduates with experience in data collection and received specific training for 7 days. There were separate set of data collectors for baseline and post intervention survey and they were remained blinded regarding the intervention. The study was approved by ethical review committee of Institute of Child and Mother Health (ICMH) and informed written consent from respondents were obtained.

Data was analyzed in the IBM PC using EPI Info and SPSS software and validated with double data entry.
Univariate and multivariate analysis was carried out and percent change of proportion between baseline and post intervention in relation to use of antenatal care, number of antenatal visits, use of skilled birth attendant for delivery and treatment of obstetric complications and number of institutional delivery were calculated at $95 \%$ confidence interval.

\section{Results:}

A total of 6077 mothers having less than one year child were interviewed. Over all sociodemographic characteristics were almost similar at baseline and postintervention survey in both intervention and control area (Table-1). Performance of both types of study centers increased but it was significantly increased in intervention centers (Table-2)

Table-I

\begin{tabular}{|c|c|c|c|c|c|c|}
\hline \multicolumn{7}{|c|}{ Socio-demographic characteristics } \\
\hline \multirow[t]{2}{*}{ Elements/Indicators } & \multicolumn{2}{|c|}{ Intervention $(n=3049)$} & \multirow[b]{2}{*}{$\mathrm{p}$ value } & \multicolumn{2}{|c|}{ Control (n=3028) } & \multirow[b]{2}{*}{$\mathrm{p}$ value } \\
\hline & Baseline & $\begin{array}{c}\text { Post } \\
\text { intervention }\end{array}$ & & Baseline & $\begin{array}{c}\text { Post } \\
\text { intervention }\end{array}$ & \\
\hline Mean age of mothers $( \pm S D)$ & $24.5 \pm 5.2$ & $24.7 \pm 5.2$ & 0.21 & $24.8 \pm 5.0$ & $24.5 \pm 4.9$ & .04 \\
\hline Mean age of menarche $( \pm S D)$ & $12.9 \pm 0.9$ & $12.9 \pm 1.2$ & 0.26 & $12.9 \pm 0.9$ & $12.9 \pm 1.2$ & .97 \\
\hline Mean age of first marriage $( \pm S D)$ & $16.6 \pm 3.3$ & $17.1 \pm 3.2$ & $<0.01$ & $16.8 \pm 3.3$ & $17.0 \pm 3.3$ & .06 \\
\hline Mean age of first pregnancy $( \pm S D)$ & $18.4 \pm 3.2$ & $18.9 \pm 3.3$ & $<0.01$ & $18.5 \pm 3.4$ & $18.7 \pm 3.2$ & .17 \\
\hline Mother's Mean years of schooling ( \pm SD) & $5.4 \pm 4.7$ & $5.4 \pm 4.6$ & .74 & $5.6 \pm 4.7$ & $5.5 \pm 4.4$ & .90 \\
\hline Mean years of schooling of the husbands $( \pm S D)$ & $6.8 \pm 5.3$ & $7.1 \pm 5.1$ & .15 & $7.0 \pm 5.1$ & $6.8 \pm 5.0$ & .20 \\
\hline Average family income in BDT $(\underline{+} \mathrm{SD})$ & $8988 \pm 10372$ & $8615 \pm 9313$ & .29 & $10074 \pm 10300$ & $9351 \pm 9310$ & .04 \\
\hline Average family expenditure in BDT $( \pm$ SD) & $7248 \pm 7260$ & $7315 \pm 7218$ & .79 & $8055 \pm 7046$ & $7950 \pm 7423$ & .69 \\
\hline
\end{tabular}

Table-II

Clinic Performance of study centers

\begin{tabular}{|c|c|c|c|c|c|c|}
\hline & \multicolumn{5}{|c|}{ Centre Type } & \multirow[b]{3}{*}{$\begin{array}{c}\% \\
\text { change }\end{array}$} \\
\hline & \multicolumn{2}{|c|}{ Intervention } & \multirow[b]{2}{*}{$\begin{array}{c}\% \\
\text { change }\end{array}$} & \multicolumn{2}{|c|}{ Control } & \\
\hline & $\begin{array}{l}\text { Pre } \\
\text { intervention* }\end{array}$ & $\begin{array}{c}\text { Post } \\
\text { intervention** }\end{array}$ & & $\begin{array}{l}\text { Pre } \\
\text { intervention* }\end{array}$ & $\begin{array}{l}\text { Post } \\
\text { intervention* }\end{array}$ & \\
\hline Registration of pregnant women & 376 & 858 & +128.19 & 781 & 847 & 8.45 \\
\hline ANC Follow up & 633 & 1339 & +111.53 & 1020 & 1227 & 20.29 \\
\hline Normal Delivery & 53 & 133 & +150.94 & 109 & 140 & 28.44 \\
\hline $\mathrm{PNC}$ & 102 & 403 & +295.09 & 345 & 317 & -8.11 \\
\hline Family Planning & 454 & 604 & 33.04 & 937 & 1175 & 25.40 \\
\hline
\end{tabular}

* The month before intervention (Dec'2001)

** The last month of intervention (Dec'2002) 
The utilization of antenatal care services was about 3 times more (6.1\% vs. 2.1\%, $\mathrm{p}<0.001)$ in the intervention area (Figure 1). The proportion of mothers who availed ANC visits 5 times or more during pregnancy were found significantly higher $(13.4 \%$ vs. $8.1 \%$, $\mathrm{p}<0.001)$ in intervention area than control (figure-2). Consultation with skilled health care providers for pregnancy complication was significantly higher (9.3\% vs. 5.7\%, $\mathrm{p}<0.001$ ) in intervention area (figure 3 ).

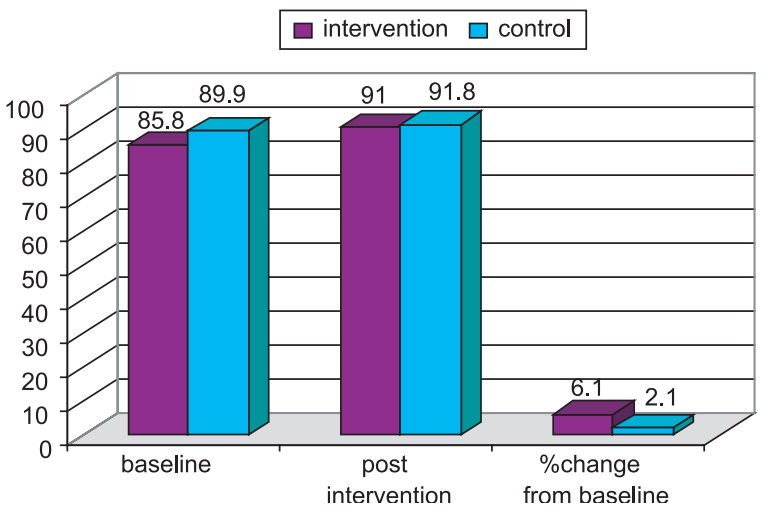

Fig.-1: Impact of Skilled Midwifery service in utilization of Antenatal care

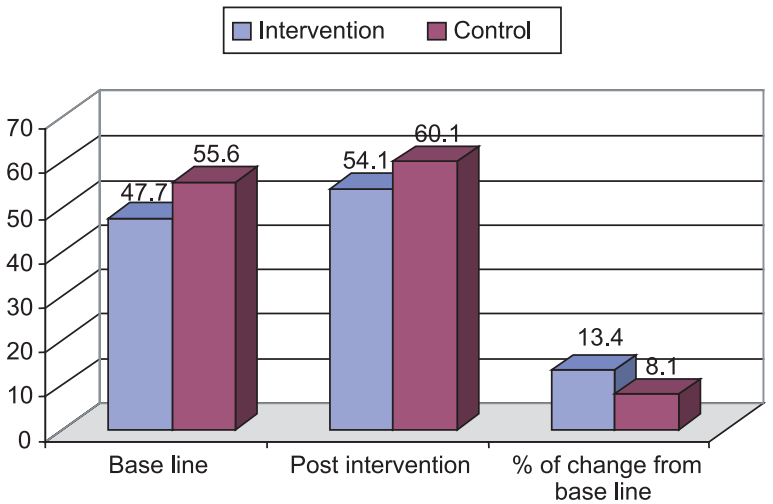

Fig.2: Impact of Skilled midwives in utilization of ANC for 5 visits or more

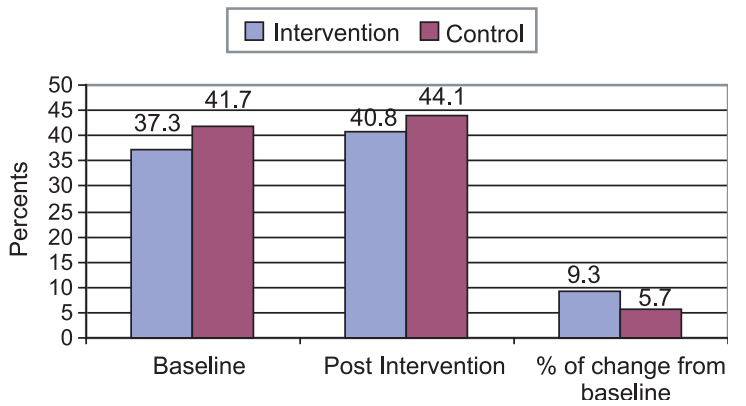

Fig.-3: Impact of Skilled midwive on the consultation of skiiled birth attendant for pregnancy complication
The increase in institutional delivery was almost double (7.3\% vs. $4.1 \%, \mathrm{p}<0.001)$ in intervention area than control (figure 4). The change in the utilization of skilled birth attendant for delivery was significantly higher (9.4\% vs. 5.8\%, $\mathrm{p}<0.001)$ in intervention and control area respectively (figure 5).

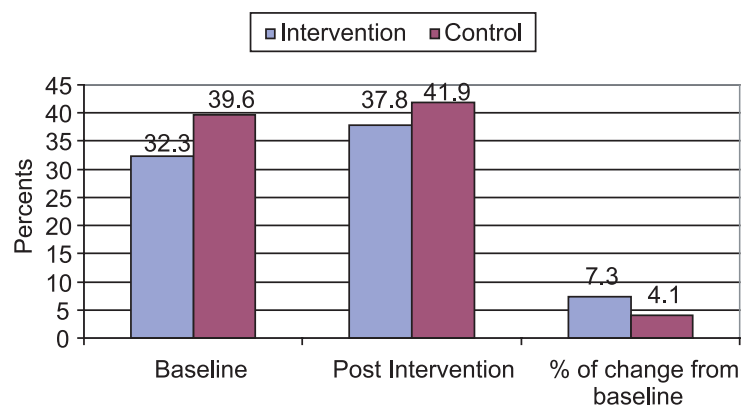

Fig.-4: Impact of Skilled Midwives in proportion of Institutional Delivery.

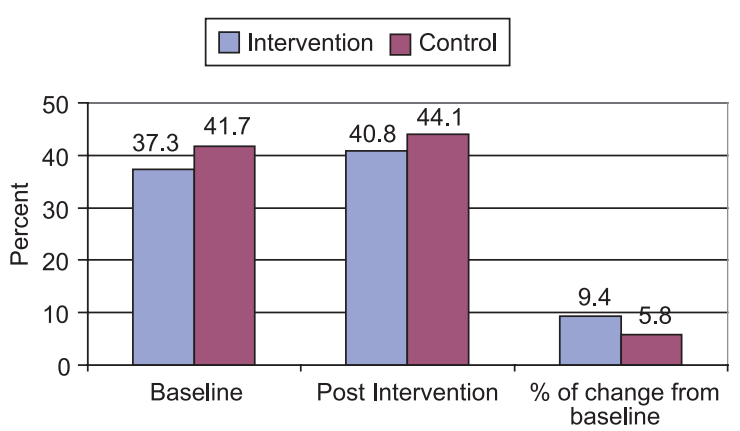

Fig.-5: Effect of skilled midwives in increasing proportion of skilled birth attendants at delivery

\section{Limitation of the study}

Measuring a change resulting from Safe Motherhood programs is a challenging issue and it is very difficult to infer certain effect explicitly to any specific intervention. To ascertain any change in mortality and morbidity would require large-scale program implementation over a sufficient length of time so impact evaluation is often discouraged and emphasis is given on process indicators for evaluation ${ }^{17}$. Different programs and services rendered by both government and non government organizations are potential confounders but they are applicable to both the control and intervention areas. Some of the changes could be reflection of natural progress with existing programs and services. 


\section{Discussion:}

The current study has tried to gather evidence by comparing selected process indicators of obstetric care services in an urban setting. It has dealt with a huge sample size of about 50,000 households each during baseline and post intervention survey. Hospital registers showed that during the intervention phase about 14,661 pregnant women received antenatal care from the five intervention centers and 1469 had skilled attendance at delivery. This also reflects the social norm of delivering at home with traditional birth attendants as reported in Bangladesh health and Demographic survey that while antenatal care coverage was $48.8 \%$ the delivery conducted by skilled birth attendant was $13 \%{ }^{7}$.

Essential drugs were supplied to about 25,908 women while they were pregnant, at labour and lactating period at the centers and about 3000 pregnant and post natal women had iron and folic acid during social mobilization and home visits. Improved performance of study centers was also related to strict supervision and monitoring and well-structured documentation of activities with monitoring tool. This had a positive role to ensure quality of services. The performance of control centers also increased during study and that could be an effect of supply of essential drugs and logistics for obstetric services. This indicated the importance of ensuring an enabling environment along with the skilled manpower to optimize their function.

Population characteristics in terms of sociodemographic factors were similar at both pre and post intervention period between control and intervention area. However, in the intervention area mean age of first pregnancy was significantly higher (18.9 Vs 18.4 years) and this could be an incidental finding or the effect of strengthening family planning services through counseling and distribution of different methods by the midwives.

Bangladesh health and demographic survey (BDHS) shows an increasing trend of coverage on maternal health indicators. In urban area proportion of women receiving any antenatal care was 59\% in 1999-2000 and in 2007 about $71 \%$ mothers received antenatal care from medical personnel $^{6,8}$. In urban area the use of health facility for delivery was 16\% in 1999-2000, 21\% in 2004 and 25\% in 2007. Treatment sought for maternal complication from a medically trained person increased from $29 \%$ to
42\% between 2004 and $2007^{7,8}$. Proportion of women utilizing antenatal and delivery services in this study was consistent with other studies in urban area. Survey by urban primary health care project reported that antenatal care coverage was 73 percent in Dhaka division and almost all contacts were with trained health personnel $^{10}$.

Evidence shows that strengthening existing maternity services brings positive changes to safe motherhood indicators. Evaluation of impact of women's right to life and health (WRLH) project in northern part of the country showed that strengthening emergency obstetric care services at district hospitals and upazilla health complex the proportion of birth at the EmOC facilities increased $119 \%$ from $5.3 \%$ to $11.7 \%$ over 3 years ${ }^{18}$. Bangladesh Red Crescent Society, developed community midwives with four years of training and junior midwives with 18 months of training, following at least eight years of basic education, and deployed them to provide delivery services through $22 \mathrm{MCH}$ centers. In the pilot project population maternal mortality declined from 410 to 230 per 100,000 live births $^{19}$. The International Centre for Diarrhoeal Diseases Research, Bangladesh (ICDDR,B) developed and deployed trained midwives in the villages to provide maternity care and established referral centre. The intervention was reported to be successful in reducing direct obstetric mortality by $3 \%$ per year in the project areas $^{20}$. However, recent analysis of their data showed that mortality declined by $68 \%$ in the ICDDRB service area and by $54 \%$ in the government served area over 30 years $^{21}$.

Developing countries that have gained success in safe motherhood like Malaysia, Sri Lanka had the experience that with greater coverage of skilled midwifery service there were improved utilization of the services, increments of institutional delivery and great dent to maternal and neonatal mortality was achieved ${ }^{22}$.

\section{Conclusion:}

Although in this study the intervention of skilled manpower (the midwives) was for a short time and covered a limited number of population the changes that occurred on utilization of routine ANC, consultation of trained health care provider for complication, number of institutional delivery and delivery by skilled persons were significantly greater than could be explained by 
natural progress of existing programs. Further research is essential to scale up the program and evaluate its impact on maternal health.

\section{Acknowledgment:}

Financial support by Asian Development Bank through Urban primary Health care project of local government Division, Ministry LGRD \& Co-operatives, GOB and co-operation of the Partner NGOs and personnel are acknowledged

\section{References:}

1. WHO. Maternal mortality in 2000. Estimates developed by WHO, UNICEF \& UNFPA. WHO 2004. Geneva

2. WHO. Maternal mortality in 1995: Estimates developed by WHO, UNICEF, UNFPA. World Health Organization, 2001. Geneva

3. UNICEF ROSA. A human rights based approach to programming for maternal mortality reduction in a South Asian context. 2003. Nepal

4. WHO. World health report 2005. Make every mother and child count. World Health Organization 2005. Geneva.

5. BDHS. Bangladesh Demographic and Health Survey 199394. Extended analysis. National Institute of Population Research and Training (NIPORT). Mitra \& associates December, 1996

6. BDHS. Bangladesh Demographic and Health Survey 19992000. National Institute of Population Research and Training (NIPORT). Mitra \& associates. 2001

7. BDHS. Bangladesh Demographic and Health Survey 2004. National Institute of Population Research and Training (NIPORT). Mitra \& associates. May 2005

8. BDHS. Bangladesh Demographic and Health Survey 2007. National Institute of Population Research and Training (NIPORT). Mitra \& associates. March 2009.

9. BMMS. Bangladesh Maternal Health Services and Maternal Mortality Survey 2001. NIPORT, MEASURE/DHS+ORC MACRO, March 2002.

10. Urban Primary Health care project. Baseline Household Survey 1999. Mitra and associates, Bangladesh In collaboration with Johns Hopkins University September 2000.
11. Starr A Interagency group for safe motherhood. The safe motherhood action agenda: Promoters for the next decade on the safe motherhood technical consultation. 18-23 October 1997, Srilanka.

12. Joint statement. WHO/FIGO/International Confederation of Midwives. "Definition of the midwife" 1992

13. Loudon I. Death in childbirth. An international study of maternal care and maternal mortality 1800-1950. 1992. Oxford University press

14. United Nations. Key actions for the further implementation of the program of action for the International conference on population and development. 1999. New York. United Nations. Para 64.

15. GOB, Bangladesh National Strategy for Maternal Health, Ministry of Health and Family Welfare Government of the People's Republic of Bangladesh, October 2001.

16. WHO. Standard of Midwifery Practice for Safe Motherhood. Volume 1: standards document. New Delhi India, WHO regional office for South East Asia

17. Wardlaw T, Maine D. Process indicators for maternal mortality programs: In Berer M, Ravindran TKS eds. Safe Motherhood initiatives: critical issues. Oxford : Blackwell science for reproductive health matters 1999: 24-30

18. Zahidul A Huque, Margaret Leppard, Dileep Mavalankar, Halida Hanum Akhter, TA Chowdhury Safe Motherhood Programmes in Bangladesh 2000

19. Islam Mt, Hossain MM, Islam M A, Hoque YA.Improvement of coverage and utilization of EmOC services in South Western Bangladesh. I J O G 2005;91:298-305

20. Ronsmans C, Vanneste AM, Chakraborty J, Ginneken JV, Decline in maternal mortality in Matlab, Bangladesh: a cautionary tale. Lancet1997. 350(Dec 20/27):1810-14.

21. Chowdhury M E, Botlero R, Koblinsky M, Sahar S K, Dieltiens G, Ronsman C. Determinants of reduction in maternal mortality in Matlab, Bangladesh: a 30 year cohort study. T he Lancet 2007; 370:1320-28.

22. Pathmanathan I, lijestrand J,Martins J M, Rajapaksa L C, Lissner C, de Silva et al. Investing in maternal health: learning from Malaysia and Sri Lanka. Washington, D C. World Bank 2003. 